\title{
Discursos para o espelho: limites e transgressões do monólogo institucional
}

Speeches to the mirror: limits and violations of the institutional monologue

Maurício Penteado Trentin 


\section{Resumo}

Um ensaio sobre os limites da prática curatorial contemporânea, suas estratégias de controle e discurso e sua possível alienação em relação a seu objeto original. É possivel que uma noção tão interessante como a compreensão da curadoria como cocriação (ou coprodução) passe a ser o discurso da prática instrumentalizada de uma curadoria com agenda própria? Pode a curadoria, atravessando seus limites desejáveis, tornarse corrosiva para a arte? Estruturas que obrigatoriamente nascem de práticas dialógicas, em um esforço de autossuficiência, tenderiam ao controle de discursos estéticos, ou pior, à produção própria de seus objetos futuros de análise?

Palavras-chave: Curadoria; Práticas curatoriais; Arte contemporânea; Discursos institucionais; Limites.

\section{Abstract}

An essay on the limits of contemporary curatorial practice, about control and speech strategies on the contemporary art circuits, and the possible alienation from its original object. Is it possible that such an interesting notion as the understanding of curation as co-creation (or co-production) turns to be the speech of a curatorial practice used as an instrument of its own agenda? Can curatorial work, by crossing its desirable limits, to become corrosive to the art? Structures that are necessarily born from dialogic practices, in an effort of self-sufficiency, would tend to control aesthetic poetic projects, or worse, would tend to the production of their own future objects of analysis?

Keywords: Curatorship; Curatorial practices; Contemporary art; Institutional speeches; Limits 
Pedem-me para desenhar um fantasma e ainda reclamam do desenho. São assim os homens.

(TAVARES, 2011.p. 78)

Quando uma noção tão interessante como entender a curadoria como cocriação ou coprodução começa a ser corrosiva para a arte?

Este artigo é uma breve reflexão sobre eventuais armadilhas da institucionalização do discurso artístico. Não pretende elucidar suas causas nem prever possiveis cenários futuros, nem é uma investigação completa sobre exemplos da prática, nem um mergulho profundo em casos similares eventualmente documentados. Ainda que de maneira breve, acredito que seja discussão válida sobre algo que parece se tornar cada vez mais corriqueiro e aceitável quando, de fato, é completamente anômalo: a substituição do objeto original pelo discurso médio do sistema ou de operadores específicos do sistema.

Pretende ser um alerta, um lembrete simples de possíveis desvios e de responsabilidades históricas da prática curatorial. Este artigo apresenta, ao final, um exemplo que, por sua radicalidade, permite mostrar um viés possível e preocupante das atividades atuais do "sistema" da arte contemporânea. O estudo procura também problematizar a questão dos limites lógicos de atuação para os autores e os curadores, ressaltando que autores e curadores aqui são funções, e não entes.

\section{Critério, controle e isenção}

Não sei se já tive uma ideia de algo que se pudesse considerar uma utopia. A utopia é o que o próximo novo artista propuser, ou sentir, ou prever e, então, o que for capaz de fazer. (entrevista de Anne d'Harnoncourt)

(OBRIST, 2010. p. 235).

Anne d'Harnoncourt era especialista na obra de Marcel Duchamp e dirigiu o Museu de Arte da Filadélfia, responsável pela maior coleção de Duchamp, de 1982 até 2008. Antes, d'Harnoncourt passou boa parte de sua vida como curadora, não só no Museu de Arte da Filadélfia como também no Instituto de Arte de Chicago, entre outras instituições. A frase acima foi dita pela curadora durante uma entrevista dada ao também curador Hans Ulrich Obrist, em diálogo que é parte do livro "Uma breve história da curadoria".

Sua frase, sua prática, assim como o trabalho brilhante feito pelo próprio Obrist, são provas de que o que planejo discutir neste artigo não é, ainda, regra. A ocasional institucionalização do discurso artístico é algo que tem se tornado mais e mais frequente, de tal maneira que me parece justificar uma reflexão breve sobre suas possíveis causas e seus eventuais efeitos. Em decorrência da brevidade deste artigo, e da própria dificuldade de documentação segura de exemplos, ative-me aqui a uma ocorrência que, por sua dimensão e clareza, serve bem ao propósito de iniciar uma discussão específica sobre o tema em questão.

O fato que me chama atenção é o quanto parte dos responsáveis por mostrar, discutir, pensar e preservar a arte tem, no circuito da arte contemporânea, ideias por vezes tão arraigadas e preconcebidas sobre os caminhos que a arte deve tomar (e também que a prática curatorial deve tomar), que se esquece de seu objeto real 
(a produção artística contemporânea real). E, na discordância entre seus modelos conceituais e os exemplos reais, simplesmente abandonam a realidade e criam uma produção em concordância com suas teorias; ou incentivam um viés claro e óbvio na produção. Um exemplo claro desta postura ocorre na entrevista que Gavin Wade dá a Paul O'Neill, transcrita a partir de trecho do livro The Culture of Curating and the Curating of Culture(s):

Many curators have also supported the idea of curating as a mode of artistic production. For example, the artist and curator Gavin Wade stated that, for him, the only distinction between artist and curator is that "the artist and the art are primary and the notion of curating and being a curator has to be secondary, and so it always comes down to the fact that really you're an artist and it's art, that the role of the curator is make art." (O'NEILL, 2012. p. 127).

Claro que é uma generalização, que o circuito da arte não é homogêneo, que as preocupações curatoriais mudam de cenário para cenário, de país para país e de museu para museu e, inclusive, em uma mesma instituição, de curador para curador, mas é uma generalização útil à discussão do caso específico que pretendo analisar.

A figura do curador criador e responsável pelo critério é, atualmente, dominante; se não enquanto realidade nacional, enquanto percepção média no circuito de arte contemporânea internacional. A ideia de que a curadoria é prática criativa não é nova e continua sendo motivo de comemoração e respeito, mas a atribuição do papel de responsável maior pelo critério da produção contemporânea dada aos curadores atuais talvez colabore para que, muitas vezes, a atitude curatorial passe de facilitador a filtro do acesso público à arte.

...since the 1990s the dominant discourse around the figure of the biennial curator created a market for a nomadic type of global curator at a time when new associations were being attached to curating, as a potentially creative form of cultural practice and as a possible career choice for artists, art historians, critics, and art administrators. (O’NEILL, 2012. p. 47).

A história da curadoria é recente, e se é que a atividade curatorial pode ser parametrizada, ela ainda não o foi propriamente. De modo que ainda temos que procurar compreender a curadoria não só por meio de teorias e métodos, que seguem raros, inconclusivos e, por vezes, discutíveis, mas também por meio de instituições, indivíduos, exposições e gestos, lendo a realidade na maior profundidade possível, aprendendo e retirando informações de exemplos reais, sejam felizes ou infelizes.

No próprio livro de Obrist, onze curadores de grande importância histórica tentam definir sua função claramente, chegam a se contradizer, e, por vezes, acabam desistindo de tal definição.

A boa curadoria da obra de um artista - isto é, a apresentação da obra em uma exposição - exige a maior compreensão e sensibilidade em relação à obra artística que um curador possa demonstrar. WALTER HOPPS (OBRIST, 2010. p. 27).

Harald Szeemann definiu as funções de Ausstellungsmacher - aquele que organiza uma exposição - como um administrador, amador, autor de introduções, bibliotecário, gerente e contador, animador, conservador, financista e diplomata. 
Esta lista aumenta, se incluímos as funções de vigilante, transportador, comunicador e pesquisador. HANS ULRICH OBRIST. (OBRIST, 2010. p. 42).

A visão do curador como critério absoluto, como que capacitado para a escolha e apresentação da parte supostamente importante da produção, parece perdurar e, em alguns casos, ser fomentada e comemorada. E, junto com tal visão, perdura a imagem de que as escolhas curatoriais são livres de interesses institucionais, pessoais, financeiros (quando pensamos em exigências de público nas instituições ou em mostras mais facilmente vendáveis para patrocinadores, públicos ou privados). Perdura, de modo geral, a noção de que o curador não só não cria um viés no critério, como ele próprio luta para "elevar" o critério da maioria. Desconfio dessa crença, tanto por minha descrença na isenção completa quanto por minhas dúvidas sobre a permanência e estabilidade de um curador que arriscasse reais transgressões e colaborações por parte de instituições tão sensíveis à sua própria reputação, como são os museus.

Parece-me, no entanto, que os erros mais evitáveis quando se pensa em curadoria não partem do receio de risco, ou de um óbvio viés curatorial, sempre visível quando exagerado, nem de um eventual acanhamento institucional, mas de um pensamento completamente útil, inteligente e defensável a respeito da curadoria: a noção de cocriação, no sentido dado por Johannes Cladders.

Sempre me considerei um "coprodutor" de arte. Não me entenda mal não quero dizer com isso que dou ordens pra um artista do tipo "agora pinte o canto superior esquerdo de vermelho!", mas antes, no sentido de participar como um museu como uma instituição de mediação - no processo que transforma uma obra em obra de arte. Sempre foi muito claro para mim o fato de que eu não precisava fazer nada para as obras que já haviam sido consensualmente declaradas arte. Ao contrário, eu estava interessado naquelas que ainda não tinham essa aprovação e, portanto, ainda eram obras, mas não obras de arte. JOHANNES CLADDERS (OBRIST, 2010. p. 77).

A ideia de que museus, instituições e curadores funcionam como mediadores, apresentando como arte novas práticas, novos processos e também novos programas poéticos ao público, ajudando a incluí-los - obras, processos, eventos e gestos - na crença de relevância daquilo que é declarado pelo circuito como obra, é não apenas uma ideia inteligente, como também prática, útil e quase sempre bem-vinda.

Ainda que nem todos creiam em teorias sistêmicas a respeito da produção contemporânea - aquilo a que o circuito dá o título e o status de arte, é, a partir daí, arte -, é fato que obras consensualmente apresentadas como obras de arte ganham em visibilidade, importância e respeito, e, por que não, aumentam suas chances de se efetivarem na condição de objetos de arte, ou seja, ganham vida enquanto possibilidades interpretativas, e não apenas enquanto objetos ou gestos. Refiro-me neste ponto a teorias sistêmicas, como a teoria de base comunicacional apresentada por Anne Cauquelin, em "Arte contemporânea", aqui, em brevíssimo, e, obviamente carente de complexidade, resumo:

Cauquelin acredita que a arte contemporânea só se faz arte contemporânea quando exposta no circuito correto, quando contida pelo continente daquilo que é 
contemporâneo, atualmente, ou o sistema da arte a que se refere. Isso suscita questões absolutamente interessantes, como se obras não expostas são arte ou serão somente a partir do início de sua exposição nos circuitos "corretos" que possibilitariam sua leitura como arte contemporânea etc. (TRENTIN, 2010. p. 21).

\section{A irrelevância do discurso quando monólogo}

Retomando o principal questionamento deste artigo, é possível dizer em que momento (ou de que maneira) uma noção tão interessante quanto compreender a curadoria como cocriação ou coprodução começa a ser prejudicial para a arte? Quando o sistema, aproveitando-se de características únicas de seu objeto original, passa a negligenciar seu objeto (os programas poéticos em suas mais variadas formas) e a substituí -lo por algo que agrade ao próprio sistema, seja por afinidades teóricas, institucionais, ou pela espetacularização necessária à manutenção do próprio sistema, que é obviamente mais ágil quando descolado de seu objeto e de sua função originais.

Poderíamos falar em uma "curadoria performática", que tenta substituir a importância de seu objeto original, a arte, perseguindo o espetáculo, achatando complexidades e especificidades em busca da comunicação rápida e da "eficácia" das mostras enquanto alcance público.

Ainda que pontualmente, tal modo de operação tem se tornado recorrente. Ser plateia do próprio espetáculo, ou aplaudir o próprio monólogo como se fosse discurso, é atitude completamente sem propósito (incluído aí o despropósito estético), mas que, paradoxalmente, tem se repetido na atividade curatorial. Deixa-se definitivamente de lado a oportunidade para o diálogo e, talvez, também uma parte interessante da produção contemporânea real.

Algumas características do objeto em si, da produção artística contemporânea, parecem colaborar para essa facilidade de engano. Engano este que pode ser percebido na substituição do objeto de estudo real por um simulacro criado pelo próprio sistema. Nos termos de Baudrillard, algo como uma falsificação completa do objeto pelo sistema que, originalmente, seria responsável por expor, discutir e manter o objeto, neste caso, a produção contemporânea. Nas palavras de Baudrillard,

Enquanto que a representação tenta absorver a simulação interpretando-a como falsa representação, a simulação envolve todo o próprio edifício da representação como simulacro.

Seriam estas as fases sucessivas da imagem: -ela é um reflexo de uma realidade profunda -ela mascara e deforma uma realidade profunda -ela mascara a ausência de uma realidade profunda -ela não tem relação com qualquer realidade: ela é o seu próprio simulacro puro. (BAUDRILLARD, 1981. p. 13)

É importante ressaltar que a arte é um campo em que a grande maioria dos que pensam, discutem, teorizam, escolhem e apresentam arte, efetivamente, não produz arte. Ao contrário de outras áreas do conhecimento. 
As associações, quando formalmente estabelecidas, que atestam as mais variadas práticas e os mais variados modos de criação e produção humanos, são, normalmente, formadas por pares que participam diretamente da mesma atividade que costumam atestar. De maneira que pesquisas médicas, por exemplo, são, normalmente, conduzidas por médicos ou por cientistas que lidam diretamente com biologia, farmacêutica e afins, e atestadas por pares. Assim como trabalhos de física são, normalmente, escritos por físicos e atestados por físicos. Matemáticos escrevem sobre matemática, economistas sobre economia, gramáticos sobre gramática, sociólogos sobre sociologia. Claro, com frequência, existe certo grau de interdisciplinaridade ou transdisciplinaridade, mas a arte é dos poucos campos em que a vasta maioria dos que pensam, discutem, teorizam, julgam e apresentam arte, efetivamente, não produz arte. Coletâneas de textos de artistas são a exceção, e não a regra, na literatura sobre arte. Assunto de profundo interesse humano, pelo encanto e mesmo pelas implicações filosóficas, é de se esperar que muitos dos que acessam a produção artística como intérpretes resolvam tratá-la como cocriadores, o que realmente são, na condição de mentes interpretadoras de símbolos estéticos com possibilidades múltiplas de leitura.

Quando a noção de coprodução abandona, no entanto, a celebração do objeto de origem e se vê como autora justificada do próprio objeto que deveria apresentar e discutir -mas jamais criar -, o limite mais crítico, entre aquele que julga e aquilo que é julgado, desaparece e o sistema perde, ainda que momentaneamente, sua justificativa de existência.

Claro que, como em muitos campos da produção e do conhecimento humanos, no decorrer da história, uma série de interdependências e relações, por vezes simbióticas e por vezes parasitárias, acontece e liga campos distintos do conhecimento e da produção. Mas pelo próprio limite daquilo que é considerado arte ser verdadeiramente terreno movediço, e o campo das outras disciplinas mais obviamente delimitado, parece ser mais fácil, e, infelizmente mais comum, supostamente se ocupar da arte quando na verdade se segue uma agenda completamente externa à arte em si, sua produção, investigação, análise, fomento e, por que não, curadoria.

Além da natureza transdisciplinar não só da produção artística, como também dos atores vários do sistema da arte, outras características do objeto facilitam a simulação, por vezes corrosiva, criada pelo próprio sistema.

\section{Transgressões possíveis}

É necessário distinguir arte contemporânea de arte atual. É atual o conjunto de práticas executadas nesse domínio, presentemente, sem preocupação com distinção de tendências ou com declarações de pertencimento, de rótulos. Não se pode realmente definir o pós-moderno como "contemporâneo" no sentido que lhe havíamos atribuído - inteiramente voltado para o comunicacional, sem preocupação estética - mas simplesmente como atual. O termo designa justamente o heterogêneo, ou a desordem de uma situação na qual se conjugam a preocupação de se manter ligado à tradição histórica da arte, retomando formas artísticas experimentadas, e a de estar presente na transmissão pelas redes, desprezando um conteúdo formal determinado. É, pois, uma fórmula mista, que concede aos produtores de obras a vantajosa posição de portadores de uma nova mensagem e desloca ou inquieta os críticos e historiadores de arte, que não sabem como captá -la nem a quem aplicá-la. (CAUQUELIN, 2005. p. 129). 
É certo que a arte, de modo geral, e, principalmente, a produção contemporânea, de modo particular, não têm limitações formais nem conceituais óbvias, e que parte do fazer artístico é a busca pela travessia de fronteiras críticas criadas anteriormente pela própria história da arte. Parte do trabalho do artista contemporâneo é exatamente redefinir o que se considera arte, alargar um campo em constante mutação e crescimento, como afirma Belting, citando Kosuth:

Joseph Kosuth achava que Duchamp devolvera à arte sua verdadeira identidade ao "perguntar por sua função" e descobrir que "a arte (nada mais) é do que a definição de arte". (BELTING, 1996, p. 37).

Transgredir, no caso da produção contemporânea, é quase regra e é parte do que se espera das obras e/ou dos processos, daí que transgressões não só não são novidade, como não são riscos imensos quando pensamos em produção poética contemporânea.

A. C. Danto, que prefere se referir à produção contemporânea como "pós-histórica", esclarece:

Poderíamos tirar proveito da palavra "contemporâneo", para cobrir quaisquer disjunções de pós-modernismos que se quisesse cobrir, mas então novamente ficaríamos com a sensação de não possuir um estilo identificável, de que não há nada que se ajuste. Mas que na verdade é a marca das artes visuais desde o fim do modernismo, que como período se define pela falta de uma unidade estilística, ou pelo menos do tipo de unidade estilística que pode ser alçada a condição de critério e utilizada como base para o desenvolvimento de uma capacidade de reconhecimento - e que, conseqüentemente, não há possibilidade de um direcionamento narrativo. (DANTO, 2005. p. 14).

Ou seja, não só uma linha histórica central parece não se sustentar, como uma quase que total liberdade formal é parte inerente do objeto. Pelos parâmetros da produção atual, e de sua condição de reconfiguração contínua, tudo pode ser arte. Mas nem tudo já é arte. A designação de um objeto qualquer, de um evento, de um processo, de um período, de uma atitude como arte é a função original do artista. Embora um programa poético possa ter aspectos pictóricos, políticos, relacionais, etc., é o ato intencional, original e primeiro o que efetiva e designa algo originalmente estranho à experiência estética como obra.

Mesmo que nem sempre envolva um ato produtivo, a arte envolve, necessariamente, um ato propositivo, ainda que $o$ ato seja somente um gesto de escolha, uma instrução, um período de convívio ou apresentação, um pensamento ou um silêncio proposital. Ainda que nenhum processo estético ou produto artístico seja concebido, que o artista não se envolva com qualquer parâmetro além de instruções iniciais para uma performance não realizada por ele, o ato propositivo é prerrogativa da função do artista.

Mesmo para um ready-made, uma escolha, e, portanto, um gesto, é realizado.

$O$ artista é aquele que tem a intenção de gerar um signo estético, mesmo que isso não envolva fisicalidade de qualquer espécie. Ou seja, o artista é aquele que tem, ainda que com as especificidades de seu programa poético, a intenção de agir no campo da arte. Nas palavras de Cauquelin: 
O divórcio entre a estética e a atividade artística tornou-se definitivo. Agir no domínio da arte é designar um objeto como "arte". A atividade de designação faz a obra existir enquanto tal. Pouco importa que ela seja isto ou aquilo, deste ou daquele material, sobre este ou aquele suporte, feita à mão ou já existente, pronta. Nesse aspecto, reconhecem-se as proposições duchampianas. Elas se desenvolvem na direção de um trabalho sobre a própria designação: a designação pode se decompor em uma pesquisa sobre a nominação - ou seja, sobre a linguagem - e em uma pesquisa sobre a exposição, pois designar é também mostrar - são os locais de intervenção da obra que estão agora em questão. (CAUQUELIN, 2005. p. 134).

\section{Limites desejáveis}

Se a fisicalidade não é limitadora e se a liberdade, não só formal quanto lógica, dada a natureza reconfigurativa, mutável e fluida da arte, é óbvia, existem limites que impossibilitam transgressões? Já que limites existem, principalmente na arte, para serem ultrapassados e reconfigurados, em um campo que espera e comemora transgressões, quais os limites que deveriam ser respeitados pela própria consideração à produção contemporânea?

Não acredito que existam limites formais, nem conceituais, nem produtivos, nem políticos, nem temporais, limites esses que seriam mutáveis geografica e historicamente, como toda produção artística demonstra, mas creio que existam limites éticos, ainda que ligados a determinadas sociedades, e, mais precisamente, limites lógicos. Não pretendo aqui tratar dos limites éticos, assunto de extrema complexidade e que extrapola a análise deste artigo, mas, sim, das limitações lógicas, mais claras, e, penso, menos discutíveis. Como discorre Danto sobre a liberdade estética:

[...] Assim, o contemporâneo é, de determinada perspectiva, um período de desordem informativa, uma condição de perfeita entropia estética. Mas é também um período de impecável liberdade estética. Hoje não há mais qualquer limite histórico. Tudo é permitido. Mas isso torna mais impositivo tentar compreender a transição histórica da arte moderna para a pós-histórica. (DANTO, 2005. p. 14).

A produção contemporânea é livre de rigor formal. Não se pode julgá-la, nem ao menos reconhecê-la, partindo de aspectos formais. Aspectos que poderiam ser importantes em determinada poética são absolutamente inexistentes em outra. De fato, não existe nenhuma linguagem obrigatória, ou condição absoluta de uso de linguagem, em termos formais. Como esclarece Kosuth, que aqui pensa a estética como ligada exclusivamente a qualidades visuais:

É necessário separar a estética da arte porque a estética lida com opiniões sobre a percepção do mundo em geral. No passado, um dos dois destaques da função da arte era seu valor como decoração. Assim, qualquer ramo da filosofia que lidasse com a "beleza", e portanto com o "gosto", era inevitavelmente obrigado a discutir também arte. A partir desse "hábito", surgiu a noção que havia uma conexão conceitual entre a arte e a estética, o que não é verdade. Essa ideia, até recentemente nunca havia entrado em conflito de maneira drástica com as considerações artísticas, até recentemente, não só porque as características morfológicas da arte perpetuavam a continuidade desse erro, mas também porque as aparentes "funções" da arte (representar temas religiosos, retratar aristocratas, detalhar arquitetura etc.) usavam a arte para encobrir a arte. (KOSUTH apud BELTING, 1996. p.214) 
Na produção contemporânea não há, inclusive, a obrigatoriedade da ação física, produtiva ou não, por parte do artista. Marina Abramovic, talvez a mais icônica artista performática, tem performances muitas vezes realizadas por atores, que funcionam exatamente com as mesmas condições e roteiros das performances realizadas pela própria artista.

VER (The Artist Is Present, MoMA, 2010) Marina Abramovic and Ulay. Imponderabilia. Originally performed in 1977 for 90 min. Galleria Comunale d'Arte Moderna, Bologna.

http://www.moma.org/visit/calendar/exhibitions/965

O artista Jeff Koons tem quadros pintados por assistentes, assim como Damien Hirst e Takashi Murakami. Artistas ainda como Maurizio Cattelan, Jeff Koons, Jan Fabre, Ai Weiwei e Gavin Turk, entre outros, utilizam artesãos e fábricas para realizar suas esculturas. (Petry, 2011).

Do "ar de Paris" de Duchamp até as esculturas públicas de Anish Kapoor, a história da arte é rica em exemplos de artistas que contratam fábricas, artesãos, engenheiros, cientistas e, por vezes, outros artistas, para realizarem suas obras.

Daí que, novamente, a interferência física do artista também não é pré-requisito da produção contemporânea. Podemos então produzir obras de arte sem artistas? Sim. Mas penso também que não podemos criar obras de arte sem criadores e, ainda que os curadores e o sistema auxiliem na promoção de obras e atestem sua importância para o campo, simplesmente abandonar o artista e a necessidade do gesto enquanto origem da obra é temerário. O gesto original, a intenção da criação do símbolo ou da experiência estética me parece ser o limite lógico que, se ultrapassado, invalida não só a produção contemporânea como o sistema que existe para promover e justificar essa produção.

Acredito que esse seja o tipo de limite lógico que a produção contemporânea, em toda sua radicalidade formal e liberdade conceitual, parece seguir respeitando, e, a meu ver, com razão. Aquele que cria, ainda que algo imaterial, gestual, momentâneo e frágil, é autor. Não como ente, mas como função. Exerce a função de autor aquele que tem o gesto original e intencional da criação.

E não temos, ainda, obras ou processos artísticos sem autores. Mesmo que um processo seja criado para problematizar a autoria, na origem, esse processo teve um autor. Ainda que a autoria seja dividida, ou que um algoritmo crie imagens generativas, o gesto inicial partiu de um ou de vários autores. E seja esse autor um indivíduo ou uma instituição, um curador ou um museu, ele agiu, por um momento, como artista. Não reconhecer o ato criativo como tal e tratá-lo como suposto ato de escolha e/ou filtragem da produção cultural real, mascarar um ato criativo como produção de critério, parece-me um limite que não deveríamos ultrapassar, ou, pelo menos, que não deveríamos ultrapassar inconscientes de termos ultrapassado. Obras que não foram criadas como obras, sejam eventos, processos, atitudes ou objetos, funcionais ou não, serão, quando nomeadas obras de arte, ready-mades propostos por um artista, esteja ele consciente ou não de sua função. 


\section{O curador autossuficiente}

O próprio sistema da arte tratou de providenciar um exemplo útil de transgressão desse tipo de limite que talvez devesse ter sido respeitado.

Exibir coisas que podem ou não ser arte junto com arte, historicamente, tem ampliado nossa percepção do que é (ou deixa de ser) ou poderia ser, ou será, arte. Desde Duchamp, e talvez antes.

A questão é que essa ressignificação de objetos comuns em obras de arte tinha sido, até 2012, e, por toda a história da arte, exclusividade dos artistas.

Algumas tentativas foram aceitas como ressignificação, outras não, mas os riscos envolvidos nas tentativas de alterar os limites do campo da arte sempre foram conhecidos pelos artistas, e, de certo modo, aceitos como condições de trabalho, como risco da ocupação. Parte do jogo é ser ou não compreendido, ser ou não aceito, alterar ou não a percepção de quem interpreta e alterar ou não os limites anteriormente marcados da arte.

Quando essa tentativa de levar outros aspectos ao museu era feita por curadores, as exposições temáticas, que incluíam documentação, objetos que não fossem obras efetivas, etc., todo o material era tratado como descrições de um processo, de interesse criativo e histórico. Ou os objetos eram celebrados em sua função original, design, comunicação, arquitetura, etc. Não tenho notícia de um museu ter decidido criar obras de arte partindo de qualquer objeto com outra função. Na verdade, não o tinha até então.

No dia 29 de novembro de 2012, a curadora sênior do MoMA, Paola Antonelli, responsável pelo departamento de arquitetura e design, anunciou com um post no blog do museu a seguinte aquisição:

Video Games: 14 in the Collection, for Starters
Posted by Paola Antonelli, Senior Curator, Department of Architecture and De-
sign

We are very proud to announce that MoMA has acquired a selection of 14 video games, the seedbed for an initial wish list of about 40 to be acquired in the near future, as well as for a new category of artworks in MoMA's collection that we hope will grow in the future. This initial group, which we will install for your delight in the Museum's Philip Johnson Galleries in March 2013, features:

- Pac-Man (1980) • Tetris (1984) • Another World (1991) • Myst (1993)

- SimCity 2000 (1994) • vib-ribbon (1999) • The Sims (2000) - Katamari Damacy (2004) • EVE Online (2003) • Dwarf Fortress (2006) • Portal (2007)

- flOw (2006) • Passage (2008) • Canabalt (2009)

VER

http://www.moma.org/explore/inside_out/2012/11/29/video-games-14-in-thecollection-for-starters/

Note que Paola, que, originalmente, é curadora de design e arquitetura, textualmente nomeia os videogames como artworks, palavra que ela cuidadosamente não emprega quando apresenta objetos de design (gráfico ou industrial) e projetos de arquitetura. 
Paola teve detratores importantes, como Jonathan Jones, que reage ao critério e aos propósitos da curadora:

Sorry MoMA, video games are not art - Jonathan Jones

http://www.guardian.co.uk/artanddesign/jonathanjonesblog/2012/nov/30/momavideo-games-art

E defensores também importantes, como o artista digital John Maeda, ligado ao media lab do MIT:

Videogames Do Belong in the Museum of Modern Art - John Maeda http://www.wired.com/opinion/2012/12/why-videogames-do-belong-in-the-museum-of-modern-art/

Inicialmente, Paola aceitou os ataques e saiu em defesa da tese original: os games escolhidos por ela eram arte. $O$ argumento foi abandonado após algum tempo e em novas entrevistas e vídeos Paola afirma que são exemplos de design interativo e não serão apresentados como arte, mas como exemplos excelentes de interação.

VER

http://video.ted.com/talk/podcast/2013S/None/PaolaAntonelli_2013S-480p.mp4

Em sua atitude original, ainda lutando para a mudança de classe dos objetos que apresentava, a curadora seguia negando o diálogo, mas aceitando os argumentos favoráveis à tese de que o museu deve sim eleger objetos variados como arte, independentemente do fato de esses objetos não terem sido concebidos e nem nomeados como obras por seus criadores diretos nem terem sido apropriados por artistas como obras. Paola segue tentando justificar suas escolhas com valores supostamente críveis e necessários aos objetos de arte (visualidade, estética, etc.). No entanto, atualmente, em novas referências à sua escolha, trata de se abster de chamá-los novamente de obras e retorna à posição confortável de curadora de design, argumentando que se trata de excelentes exemplos de interface. É sobre essa primeira atitude, a aguerrida defesa de sua decisão arbitrária supostamente transfigurativa, que me parece valer a pena uma avaliação algo mais profunda.

Independentemente de qualquer qualidade funcional, lógica ou intrínseca, os softwares escolhidos por Paola seguem, dentro ou fora do museu, sendo o que são, jogos comerciais. Ótimos ou não, felizes ou infelizes em sua busca por qualidade experiencial dentro de suas bases próprias, eu respeitaria imensamente a decisão de tratá-los como eventos importantes dentro de sua classificação real: jogos.

É importante delinear este ponto: considero inteligente e feliz a ideia de se levar mais da produção humana para os museus, mas em seus termos, próprios, e não nos termos tidos como respeitáveis pelos museus. Por que, no andar de design, objetos de desenho industrial inteligente, de design gráfico, de arquitetura, são lidos em seus termos e não enquanto obras de arte, que não o são no sentido mais óbvio do termo, mas os jogos 
terão que ser vistos como arte ou não serão bem-vindos nos museus em seus próprios termos, softwares, games, exemplos de interação ou de produção humana, sem que se tenha que colar o adesivo de obra e a suposta valoração que o objeto de arte possui?

Se qualquer coisa pode ser uma obra de arte, mas algumas coisas ainda não o são e aguardam um gesto (de escolha, no mínimo) para transformá-las em arte, o museu se adiantou na sua tarefa curatorial e se tornou, por um instante, artista.

O museu fez a escolha e autorizou os games como arte, portando-se como criador, não como um guardião do que é criado, nem como cocriador. A atitude original, e não a atitude revisada pós-crise, mostra que o museu e a curadora se sentiam autorizados a nomear, de uma vez, todo um campo da produção humana como arte, e se adiantaram tratando de julgar os exemplos, portando-se não apenas como a chancela, mas como o critério de algo que obviamente era objeto estranho à sua prática.

Seja qual for o motivo para a transgressão do limite lógico do museu, sua separação de seu objeto, o que garante sua base de existência primeira, os desdobramentos podem ser interessantes.

Se qualquer coisa pode ser arte, um pão, uma equação, um acelerador de partículas, uma lata amassada de refrigerante, um game ou outro software qualquer, parte da diversão era aguardar que um artista dissesse "meu game é arte, e não só mais um game". Nesse caso, o game seria um formato, um suporte, mas a experiência que o artista trataria não seria simplesmente a de interação e diversão, mas mais crucial, a fruição e a interação com o software enquanto obra de arte experiencial, interativa, maleável.

O museu roubou dos artistas esse momento e decidiu, por si, criar um ready-made.

Já pensei, algumas vezes, em criar ready-mades digitais, tratar um software pronto como arte. Um Excel, por exemplo, algo esteticamente infeliz. Mas demorei. O MoMA foi mais rápido e criou não só o ready-made digital, mas uma coleção inteira que será tratada às vezes como design, às vezes como arte, mas sempre como possibilidade de interação e, obviamente, como pauta de discussão. Já sabendo que ser artista é uma função possível, e não liberada apenas a determinadas entidades, seres, o museu se tornou, enquanto se fingia de curador, artista. Isso por si só parece interessante, revolucionário e perigoso.

Se a curadora Paola Antonelli admitisse que se trata de uma visão individual sua, que está agindo como artista, ótimo. Seguir agindo, porém, curatorialmente, mas decidindo o que é e o que não é arte dentre qualquer tipo de produção humana é, no mínimo, temerário.

A perspectiva abordada oferece também algum espaço para diversão. $O$ museu parece não ter decidido se vai explorar toda a base de softwares ou se apenas games. Talvez hardwares, mais complexos de armazenar, poderiam ser vistos como arte e não só como design. Ou considerar parte da pornografia on-line arte. Mas qual parte? A parte cobrada ou a parte free tour? O museu poderia, em outra atuação como artista, considerar de uma só vez todos os extintores pendurados em museus e galerias, em todo o mundo, arte. Ou pelo menos os seus próprios extintores. Eu adoraria. Outros artistas, vendo o museu surrupiar-lhes o privilégio de criar arte, talvez não.

Plausíveis ou absurdas, relevantes ou gratuitas, interessantes ou não, em muitos aspectos, escolhas como essas seriam análogas à escolha da curadora, 
decidindo arbitrariamente que algo, a partir de seu gesto, alteraria seu status original, e passaria de produção comercial (ainda que com valores estéticos) à obra de arte, sem que para isso fosse necessário qualquer responsável poético real para o gesto transfigurador que não a própria curadora. É talvez o exemplo atual de sublimação da figura do artista, da final substituição da obra pela moldura, encarnada aqui em sua versão mais espetacular, a da instituição.

Já sabemos que os games (e tudo mais, extintores, talheres descartáveis, louça sanitária) podem ser arte, não que sempre o sejam, mas sempre poderiam sê-lo.

A questão, que me parece agora mais grave do que se os games deveriam ou não ser apresentados como arte por um museu (e não escolhidos como arte por seus criadores), é a seguinte: se o museu, último santuário de respeito às atitudes criadoras, decide atuar como artista, quem, no futuro, atuará como museu?

Sigo interessado em analisar os limites da atuação no campo da arte, sejam artísticos, teóricos, curatoriais ou institucionais. Limites que podem ser usados como referenciais ou como obstáculos, como ferramentas ou como elementos que devam ser ultrapassados, em quaisquer processos criativos, mas, principalmente, em atitudes críticas como as presentes na produção contemporânea.

Daí que a discussão aqui não é puramente processual, mas se refere o tempo todo ao processo, já que a arte é criada e apresentada, não só levando em conta o sistema da arte, mas, na grande maioria das vezes, por meio desse mesmo sistema. Discutir, pensar e perceber as razões atuais desse sistema, sejam estéticas, políticas, comunicacionais ou econômicas, parece exercício crucial para aprofundar a compreensão sobre as particularidades do processo criativo e também sobre as possibilidades da produção contemporânea. 


\section{Referências}

BAUDRILLARD, Jean. Simulacros e simulação. Lisboa: Relógio d'água, 1981. BELTING, Hans. Likeness and Presence. Paperback ed. Chicago: The University of Chicago Press, 1996.

.O fim da história da arte. 1ํㅡㄹ ed. São Paulo: Cosac Naify, 2005.

BENJAMIN, Walter. A obra de arte na era de sua reprodutibilidade técnica. In Obras escolhidas - Magia e técnica, arte e política. São Paulo: Brasiliense, 1996.

BOURRIAUD, Nicolas. Estética relacional. São Paulo: Martins Editora, 2009. CAUQUELIN, Anne. Arte contemporânea. Uma introdução. São Paulo: Martins Editora, 2005.

DANTO, Arthur C. A transfiguração do lugar-comum. Uma filosofia da arte. 1aㅡ ed. São Paulo: Cosac Naify, 2005.

Após o fim da arte. A arte contemporânea e os limites da história. 1a ed. São Paulo: Edusp, 2006.

FERREIRA, Glória; COTRIM, Cecilia. Escritos de artistas: anos 60/70. $2^{a}$ ed. Rio de Janeiro: Jorge Zahar Editor, 2009.

GREENBERG, Clement. Estética doméstica. São Paulo: Cosac Naify, 2002. OBRIST, Hans Ulrich. Uma breve história da curadoria. São Paulo: Bei, 2010.

O'NEILL, Paul. The Culture of Curating and the Curating of Culture(s). Cambridge: MIT Press, 2012.

PETRY, Michael. The Art of Not Making. New York: Thames \& Hudson, 2011. TAVARES, Gonçalo M. O senhor Valéry e a lógica. Rio de Janeiro: Casa da palavra, 2011.

TRENTIN, Maurício. Possibilidades comunicacionais e relacionais entre obras de arte e seus intérpretes como base para categorização da produção contemporânea. São Paulo: COS_PUCSP, 2010.

TOMKINS, Calvin. Duchamp. 1aㅡ ed. São Paulo: Cosac Naify, 2005.

\section{Autor:}

Maurício Penteado Trentin

Doutorando em Poéticas Visuais

Programa de Pós-Graduação em Artes Visuais da Escola de Comunicações e Artes da Universidade de São Paulo - ECA/USP

São Paulo, São Paulo

Brasilmauricio@mauriciotrentin.com 